\title{
TECNOLOGIAS DIGITAIS E QUALIFICAÇÃO DO PROCESSO DE PROJETO INCLUSIVO
}

\author{
SILVA, Luísa \\ Faculdade Meridional IMED, e-mail: Ivisa.projetospredilar@gmail.com \\ MUSSI, Andrea \\ Faculdade Meridional IMED, e-mail: andrea.mussi@imed.edu.br \\ SILVA, Thaísa \\ Faculdade Meridional IMED, e-mail: thaisa.silva@imed.edu.br
}

\begin{abstract}
RESUMO
O trabalho apresenta o cenário do uso da programação por arquitetos que criam suas próprias ferramentas de projeto por meio da programação e personalização de plug-ins utilizando um software BIM. Busca identificar de que formas as tecnologias de projeto podem colaborar com a qualificação do mesmo, no que se refere à participação de Pessoas com Deficiência Visual (PcDV) durante todo o processo. Por isso, seu objetivo é identificar parâmetros, mensuráveis para linguagem digital, equalizadores entre normativas, PCDV e projetistas, que visem a qualificação e a inserção de pisos voltados às PCDV. A pesquisa utiliza o codesign para a participação efetiva e prática das PCDV. E, da estratégia do Design Science Research para propor um plug-in para a plataforma Autodesk Revit, utilizando o software Dynamo, que possibilite aos projetistas acessarem parâmetros de piso, diretamente em sua plataforma de projetação que inter-relacione as necessidades espaciais das PCDV e os parâmetros das normas técnicas de forma mais assertiva. O artigo apresenta a programação da ferramenta. Apresentase, portanto, contribuições teórica, prática e acadêmica pois a pesquisa busca ampliar o conhecimento e avança na utilização de formas metodológicas que buscam diminuir as lacunas existentes do problema em questão.
\end{abstract}

Palavras-chave: Projeto em Arquitetura e Urbanismo, Pessoa com Deficiência Visual, Parâmetros, Codesign, Design Science Research.

\begin{abstract}
The paper presents the scenario of the use of programming by architects who create their own design tools by programming and customizing plug-ins using BIM software. It seeks to identify in which ways the project technologies can collaborate with the qualification of the same, regarding the participation of Persons with Visual Disability (PCDV) throughout the process. Therefore, its objective is to identify parameters, measurable for digital language, equalizers between normative, PvDV and designers, that aim at the qualification and the insertion of floors directed to the PCDV. The research uses the codesign for the effective and practical participation of the PCDV. And from Design Science Research's strategy to propose a plug-in for the Autodesk Revit platform using Dynamo software that enables designers to access floor parameters directly on their design platform that interrelates the spatial needs of the PCDVs and the parameters of technical standards more assertively. The article will present the tool's programming. Therefore, theoretical, practical and academic contributions are presented because the research seeks to broaden the knowledge and advances in the use of methodological forms that seek to reduce the existing gaps of the problem in question.
\end{abstract}

Keywords: Project in Architecture and Urbanism, Person with Visual Impairment, Parameters, Codesign, Design Science Research.

SILVA, L.; MUSSI, A.; SILVA, T. Tecnologias digitais e qualificação do processo de projeto inclusivo. In: SIMPÓSIO BRASILEIRO DE QUALIDADE DO PROJETO NO AMBIENTE CONSTRUÍDO, 6., 2019, Uberlândia. Anais... Uberlândia: PPGAU/FAUeD/UFU, 2019. p. 801-811. DOI https://doi.org/10.14393/sbqp19074. 


\section{INTRODUÇÃO}

A dificuldade de equalizar as necessidades para Pessoas com Deficiência (PcD) em projetos arquitetônicos é um tema amplamente discutido no mundo. A todo momento surgem pesquisas com novas experiências e metodologias para identificar a maneira mais assertiva para que isso aconteça. Bianchin e Heylighen (2017), afirmam que essa busca da inclusão social de maneira geral se torna mais difícil, pois ao inserir maneiras de acessibilidade em projetos, buscando atender o mais vasto número de pessoas, se torna impossível atender a todas as diferenças humanas de uma só vez, sem elencar problemas principais. E, ao fazer isso, projetistas são obrigados a desconsiderarem necessidades que são de extrema importância para outro grupo específico de pessoas.

Neste contexto, entre os elementos que são inseridos em projetos voltados às PCDV, se destaca o piso tátil. Contudo, antes mesmo do elemento ter se consolidado com padrões definidos em seu país de origem, ele foi replicado e apresentou diversos problemas e fragilidades, tanto na padronização de cores, como na especificação de seus materiais. Com isso, diversos tipos de pisos foram elaborados pelos mais diversos países, com inúmeras e distintas padronizações e não foi encontrado, até o momento, nenhuma pesquisa que demonstrasse total satisfação dos usuários com esse elemento.

Mesmo que aconteçam avanços no que se refere ao estudo de métodos que incluam as PCDV no processo de projeto, os arquitetos saem da vida acadêmica para suas carreiras profissionais replicando os parâmetros técnicos constados nos textos normativos, sem reais noções e propriedades de questionamentos se tais parâmetros satisfazem os problemas de acessibilidade a que se propõem. Fator que acontece tanto pela falta de conhecimento da vivência dessas pessoas, como pela necessidade do mercado para que os processos de projeto sejam cada vez mais ágeis.

O artigo exposto realiza uma discussão a respeito do segundo fator, pois os avanços das tecnologias digitais de projeto propiciaram aos arquitetos otimizarem tempo durante o processo de projeto por meio da elaboração de algoritmos que possibilitam a programação de plugins utilizando softwares BIM (Building Information Modeling). Isso faz com que seja possível que comandos e ações sejam customizadas a partir de variáveis definidas pelo projetista no ambiente de projetação.

Esses algoritmos são procedimentos para endereçar problemas utilizando uma série finita de passos, que sigam uma sequência lógica e consistente (NATIVIDADE; VENTURA, 2009). Assim, algoritmos não são exclusivamente digitais e podem ser aplicados na resolução de qualquer tarefa cotidiana. Brigitte e Ruschel (2018) destacam como é comum observar-se a criação de algoritmos relacionados ao desempenho quantitativo, acústico, lumínico e térmico, mas que pouco se vê algoritmos qualitativos que explorem a relação ser humano-ambiente.

Essas estratégias algorítmicas têm se tornado particularmente importantes por servirem de base para distintas abordagens metodológicas durante processos de projetos (MEREDITH, 2008). Para Hudson (2010), o processo paramétrico de projeto é definido como o desenvolvimento de um modelo ou descrição de um problema, onde a representação é baseada nas relações entre objetos controlados por variáveis: os parâmetros. 
Na pesquisa os parâmetros são resultados da equalização entre normativas técnicas de acessibilidade, PCDV e projetistas. Visam a qualificação do processo de projeto quando este objetiva inserir pisos voltados às PCDV, por meio da elaboração de um plug-in utilizando o Autodesk Revit (AUTODESK, 2017), um software BIM e o Dynamo (DYNAMO, 2018), um software de programação de linguagem visual.

Eastman (1968), muito antes do surgimento do conceito BIM, conseguiu demonstrar a descrição de atividades repetitivas realizadas ao longo de um processo de projeto. Descreveu resultados de um estudo exploratório das diversas maneiras que seriam possíveis para a resolução de um layout de banheiro, no qual projetistas verbalizavam suas sequências de decisões projetuais. Ao final do processo, o autor chegou a onze manipulações que podem ser explicadas como uma rotina de passos para resolução de um problema específico.

As manipulações se assemelham às funções que um plug-in é capaz de executar por meio da descrição de algoritmos que significam a leitura de um sistema lógico divisível em vários subsistemas pelo reconhecimento de padrões provenientes de atividades realizadas por projetistas, mesmo que inconscientemente, durante as etapas de um projeto (JUNIOR; CELANI, 2018).

Eastman (1968), contudo, relata que apenas uma máquina seria capaz de realizar com paciência as simulações recursivas dos protocolos gerados a partir das regras que foram estabelecidas. Sendo assim, o que o autor explana em seu trabalho se assemelha ao que está acontecendo na nova revolução da arquitetura contemporânea que busca, por meio da formulação de algoritmos, programar as atividades repetitivas em um processo de projeto que podem ser estabelecidas por meio de um conjunto de regras. Um dos pontos mais importantes do trabalho do autor, com extrema relevância para a pesquisa a ser apresentada é de que ao programar por verbalização as preferências de arquitetos durante um processo de projeto, demonstra-se possível que, se traduzidas em rotinas lógicas, as preferências de usuários também podem ser programadas.

Por isso, o objetivo do artigo é discutir o uso de estratégias de Design Science Research (DSR) e do Codesign para otimizar ferramentas de suporte ao projeto quando este é voltado à projetos que visem a inclusão de PCDV. Dessa forma, será demonstrado a importância do desenvolvimento de códigos de construção relativos à arquitetura inclusiva para que as preferências de usuários possam ser aliadas à parâmetros normativos e possam ser utilizadas por meio de uma ferramenta digital de projeto. A pesquisa busca demonstrar a importância de explorar a combinação entre design algoritmo e plataforma BIM como uma forma de qualificar o processo de projeto inclusivo em arquitetura.

\section{METODOLOGIA}

Para que os parâmetros utilizados para a programação do plugins contenham as preferências das PCDV, a pesquisa faz uso do Projeto Colaborativo (PC), ou codesign, que centraliza as tomadas de decisões do processo de projeto no usuário e afirma uma metodologia que busca compreender e aprender com o usuário a sua expertise a respeito da temática abordada num determinado projeto e contexto. Segundo Carneiro, Barros e Zibel (201 1), essa participação 
de usuários na concepção de projetos possibilita discussões aprofundadas sobre as diferentes necessidades existentes. Pois, ao fazer uso do codesign, é possível que se promova uma linguagem comum de projeto, para que tanto os usuários quanto os profissionais do projeto possam se entender e se expressar (CAIXETA; FABRICIO, 2018). E, de acordo com as atividades cotidianas dos usuários se delimitam possibilidades de projeto no qual são realizadas trocas constantes para o andamento do projeto.

O infográfico (Figura 1) busca demonstrar, a intenção da pesquisa em utilizar o codesign como um conjunto de metodologias colaborativas que buscam centralizar as PCDV no processo de projeto para que sejam extraídas suas preferências a partir de parâmetros normativos em relação ao piso tátil. Demonstra que ao utilizar-se da estratégia do DSR que, segundo Dresch et al. (2015), é voltada para a criação de artefatos como forma de operacionalizar prescrições para problemas específicos, será possível propor uma ferramenta de projeto. Essa ferramenta será elaborada pela equalização de todas as variáveis da pesquisa: as normas técnicas, as preferências das PcDV, o piso tátil e arquitetos.

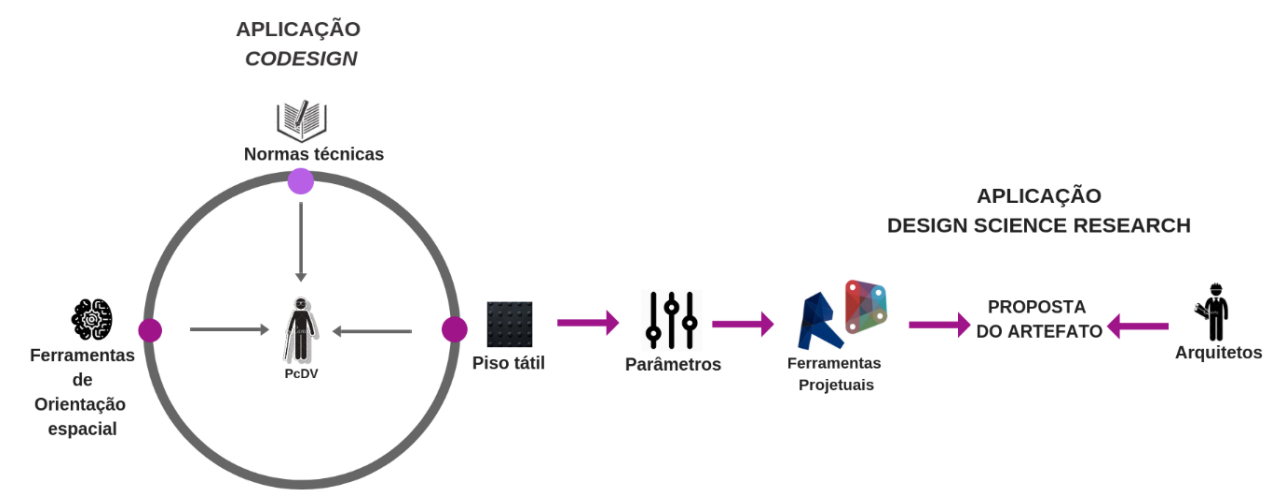

Figura 1 - Processo metodológico utilizado pela pesquisa -

Fonte: Autores (2019)

\section{RESULTADOS}

\subsection{Equalização teórica}

O primeiro passo para realizar a equalização foi um estudo aprofundado nas legislações que abordam os direitos das PCDV ao espaço construído. Dessa forma, por meio de pesquisas de referências legislativas foi estudado a evolução da garantia do direito de acessibilidade no Brasil. Isso foi importante pois possibilitou uma base teórica consistente para analisar a situação que as normativas atualmente buscam promover a acessibilidade nos espaços para PCDV e, como consequência, as normativas mais analisadas foram as que citam o piso tátil em especial a norma técnica brasileira NBR 16537 (ABNT, 2016).

Posteriormente, ao aprofundar o conhecimento quanto a origem do piso tátil, sua utilização como um elemento de orientação espacial para as PCDV e sua efetividade para o objetivo pelo qual ele é proposto nos projetos, algumas questões começaram a se tornar proeminentes. No início da pesquisa o 
interesse pelo estudo de elementos de orientação espacial para PCDV, além do Brasil, logo se configurou pelos Estados Unidos devido ao fato do país ser berço do termo "barriers free design", que deu origem ao conceito do Desenho Universal, conhecido atualmente como uma concepção de projeto que busca a inclusão das pessoas holisticamente e não de um projeto que se desenha para abranger necessidades especiais.

Depois, começaram-se a perceber pelas pesquisas iniciais que o país utilizava o piso tátil de alerta somente em alguns pontos específicos e não utilizava piso tátil direcional, como acontece em vários lugares do mundo, a exemplo do Brasil. Sendo este o elemento de maior popularização como forma de inclusão das PCDV nos espaços construídos, questionaram-se os motivos pelos quais esse elemento é pouco explorado pelo país para identificação de quais seriam então os elementos utilizados para a orientação destas pessoas. Somase ainda, que como resultado de pesquisas exploratórias de outros tipos de ferramentas de orientação espacial também se identificou que o país possui os principais programas de orientação e mobilidade para PCDV do mundo e é berço de pesquisas de universidades como do Massachusetts Intitute of Technology, que possuem laboratórios específicos para estudar e compreender os processos de orientação espacial das PCDV (LAHAV; MIODUSER, 2004; LAHAV; SCHLOERB; SRINIVASAN, 2009; MUSSI, 2018).

Com esses questionamentos realizados se iniciaram o levantamento de dados específicos para compreender como a acessibilidade dos espaços construídos aconteceram nos Estados Unidos e no Brasil, para que se pudesse caracterizar os motivos pelos quais essas diferenças se configuram e, identificar parâmetros que possam agregar conhecimento na elaboração do plugin.

As respostas para todos os questionamentos se encontram na pesquisa de Schwartz (1993) que afirma que a mudança da perspectiva do país para que as PCD deixassem de ser segregadas da sociedade e para que o país ganhasse uma posição de modelo mundial para o tema foram apoiadas por explicações socioeconômicas. O grande número de programas de auxílio de renda e outras formas de assistência direta para PCD geravam grandes custos para o governo.

Schwartz (1993) afirma que esse argumento econômico, ou de custobenefício, refletiu-se mais fortemente nos diversos programas de reabilitação profissional adotados para as PCD nos Estados Unidos. A maior parte das legislações que as inserem, estabelecendo o direito ao emprego e o acesso a todos os setores da sociedade, foram aprovadas com o objetivo de melhorar a capacidade dos indivíduos de gerar atividade econômica e maior renda pessoal para si mesmos. Todos estes esforços foram direcionados, tanto para aumentar a força de trabalho, como para diminuir os programas de auxilios de renda.

Segundo O'Leary, Lockwood e Taylor (1996), os grupos de defesa nacional para cegos dos Estados Unidos tinham visões conflitantes sobre a necessidade de utilização do piso tátil. O The National Federation for the Blind em contraposição ao American Council of the Blind e a American Foundation for the Blind não eram favoráveis à utilização dos pisos táteis pois afirmavam que, essas superfícies sendo amplamente usadas, levariam as PcDV a não perseverarem em suas aprendizagens de orientação e mobilidade. 
Essas divergências entre os países tanto nos treinamentos utilizados para que essas pessoas efetivamente participem da sociedade, bem como os diferentes incentivos de políticas públicas fizeram com que os Estados Unidos tenham diversos elementos e ferramentas de orientação espacial que fazem com que o piso tátil de alerta pouco seja utilizado e o direcional, nunca tenha sido utilizado pelo país. Todas as diferenças encontradas, bem como as características e elementos balizadores utilizados pelo país que cumprem a função de orientar as PcDV nos espaços construídos estão sendo levados em consideração para a elaboração do plugin e serão inseridos na programação, mesmo que em forma de textos, para que o arquiteto possua maior plurivalência de conhecimentos no momento de inserir o piso tátil no projeto.

\subsection{Equalização prática}

Outro fator determinante na busca pela equalização são as estratégias metodológicas utilizadas para a efetiva aproximação com as PcDV para que, na prática, se entenda como esses indivíduos se relacionam com um determinado ambiente. O método escolhido foi o Passeio Acompanhado (Figura 2), que busca aprender a expertise do usuário a partir de situações concretas vivenciadas por eles, avaliando suas dificuldades e facilidades para utilizar os espaços de forma adequada. Estas estratégias possibilitam ao pesquisador identificar elementos que não constam em normas técnicas como, por exemplo, determinar quais são as suas preferências para se locomoverem, quais as principais guias de balizamento que são utilizadas por eles. Não foram desconsiderando os ambientes externos, pois é importante para a pesquisa esclarecer os conceitos de orientação espacial e percepção acerca dos processos de compreensão da orientação e mobilidade das PCDV no espaço construído como um todo.

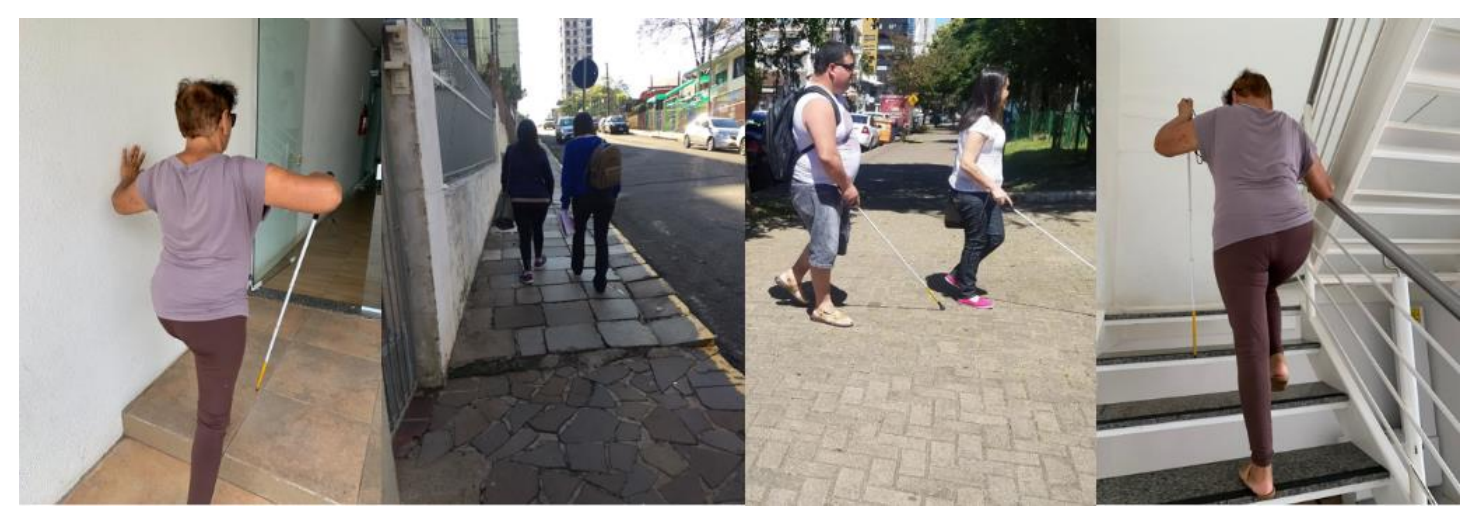

Figura 2 - Aplicação do codesign por meio da metodologia de Passeio Acompanhado Fonte: Autores (2019)

\subsection{Programação do Plugin}

Com os resultados já obtidos a partir das equalizações anteriores, o plugin irá focar no elemento em comum entre as normas técnicas estudadas, Brasil e Estados Unidos, que será o piso tátil de alerta. Também se optou por essa escolha pois, pelos resultados preliminares obtidos com as estratégias da equalização prática, apresentadas anteriormente, já se supõe que o piso direcional não tem contribuição nos deslocamentos dos participantes já que, mesmo quando identificado, é desconsiderado e substituído por outros elementos balizadores do ambiente. 
O primeiro passo na definição das atividades do plugin foi especificar quais seriam as suas funcionalidades gerais. Dessa forma, através da funcionalidade "Classificar os elementos da vista de projeto" (Figura 3), o Autodesk Revit selecionará todas as famílias que são necessárias para procurar os parâmetros, conforme prescrito pela NBR 16537 (ABNT 2016).

Os principais agrupamentos de projeto necessários para a inserção do piso tátil serão aqueles compostos pela família de portas; família de elevadores e plataformas elevatórias; família de escadas, rampas, incluindo seus degraus; família de escadas ou esteiras, família de equipamentos de uso, serviço ou serviço; e, finalmente, famílias de elementos suspensos que devem ser classificados como qualquer tipo de elemento dentro do projeto que tenham uma altura entre 0,30 e 2,10 metros. Neste ponto, a ferramenta já deve digitalizar para detectar balizas no projeto, como superfícies verticais que já poderiam servir como guia. Esses são os elementos-chave para verificação.

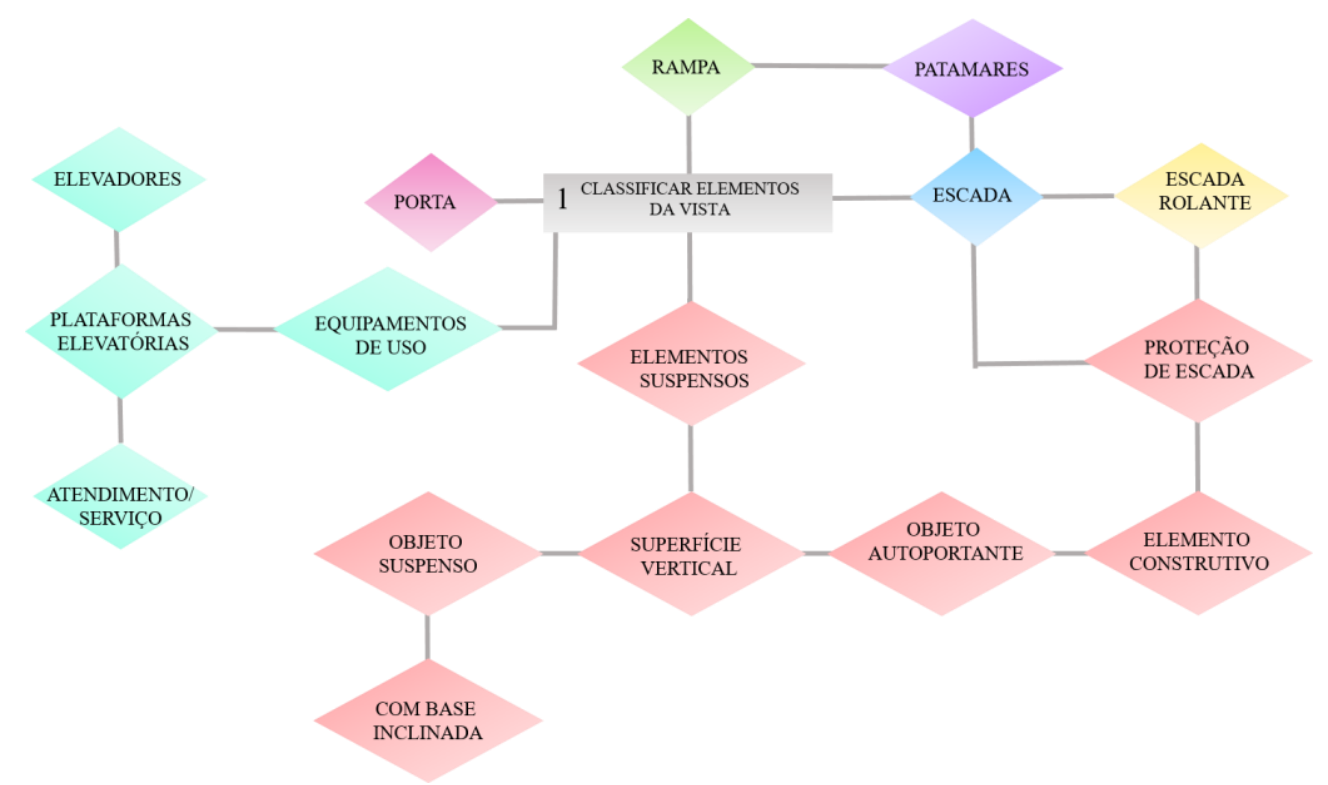

Figura 3 - Funcionalidade que classifica os elementos de família por vista de projeto Fonte: Autores (2019)

A estratégia mais eficaz foi iniciar pela rotina que interseccionou as geometrias (Figura 4) necessárias para retirar os parâmetros de largura da categoria do elemento selecionado pela funcionalidade anterior (portas, escadas, rampas e elevadores, etc). Devido à rotina ser realizada com cenários variados para cada categoria de elemento, no artigo apresentado será demonstrado a execução das rotinas utilizadas para inserir família de piso tátil de alerta em uma porta. A rotina se inicia pela criação de dois planos $(x, z)$ a partir das geometrias de referências bases selecionadas. As referências base para as portas, por exemplo, serão a categoria de elementos que contemplam as paredes, pois somente a partir dessa intersecção que é possível identificar o parâmetro de largura, necessário para delimitação dos pontos por vetor, resultantes do 'geometry translate', que usa vetores para traduzir uma geometria. Para elevadores segue-se o mesmo raciocínio, contudo, devido às escadas e rampas não necessariamente estarem inseridas no ambiente de projeto relacionadas à parede a estratégia mais adequada se dará pela intersecção das próprias categorias de elementos com o piso de referência. 


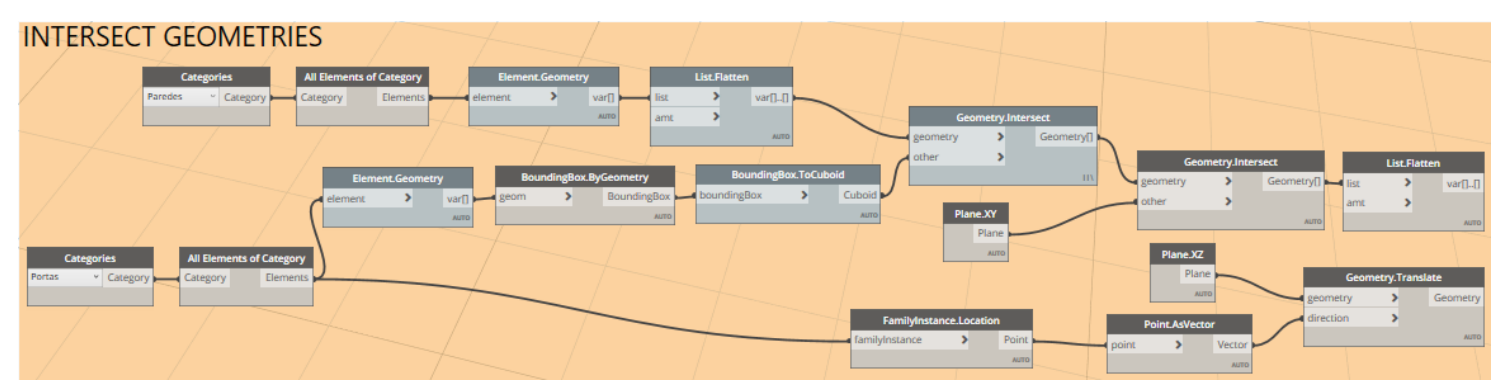

Figura 4 - Primeira rotina para intersecionar geometrias -

Fonte: Autores (2019)

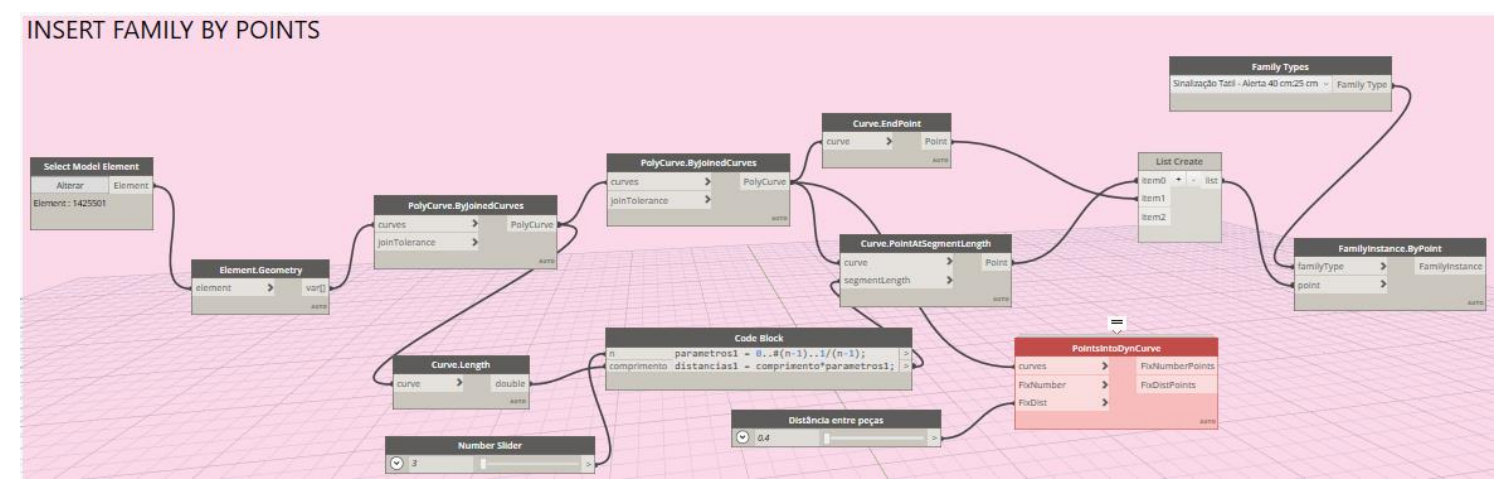

Figura 5 - Segunda rotina para inserir família por pontos -

Fonte: Autores (2019)

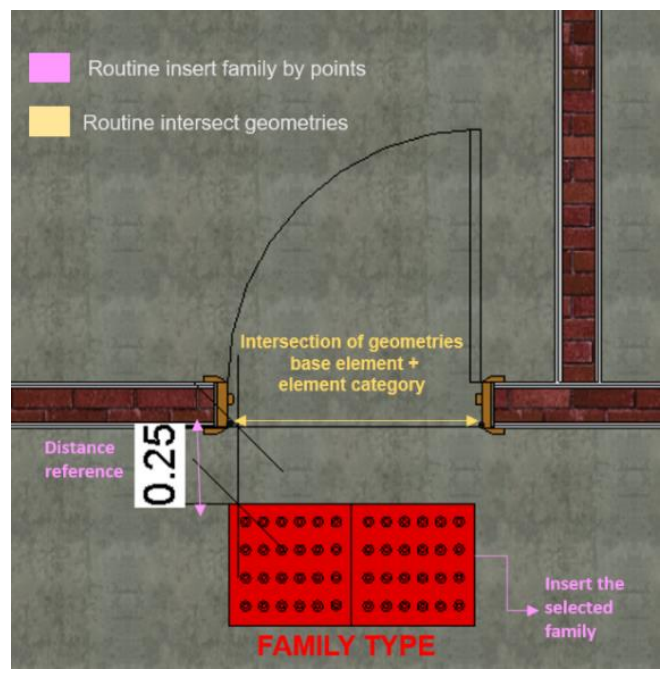

Figura 6 - Funcionalidade selecionando o elemento da categoria de portas

Fonte: Autores (2019)

A segunda rotina (Figura 5) busca a partir dos resultados dos pontos elaborados pela rotina anterior, inserir uma linha de referência entre eles para a colocação da família de piso tátil. Essa rotina será a que conterá os parâmetros resultantes das equalizações práticas com as PCDV, definindo a distância da família em relação ao elemento, características da família, número de peças e a distância entre elas. Devido aos resultados dos passeios acompanhados demonstrarem que o piso, embora a NBR 16537 (ABNT, 2016) defina que deve possuir uma largura de peça que esteja entre 0,25 e $0,60 \mathrm{~cm}$ e que, consequentemente, fica a cargo do projetista definir, a peça da família de piso tátil que será inserida pelo plugin deverá possuir $40 \mathrm{~cm}$ de largura, pois 
é o denominador em comum definido pelos participantes da pesquisa como 0 ideal.

A rotina resultou na identificação dos pontos a partir da intersecção das geometrias necessárias para a categoria de elemento específica (portas) para que a inserção do tipo de família, com parâmetros de largura e dimensões, seja especificada pelo plugin de acordo com a preferência das PCDV, à uma distância de referência da linha guia também preferível e definida pelas PCDV e com a possibilidade de ajustes para outras situações como escadas, rampas e elevadores (Figura 6).

\section{CONSIDERAÇÕES FINAIS}

A baixa qualidade de projetos que incluam elementos para orientação de PCDV no Brasil é frequentemente relacionada à uma metodologia desestruturada no qual aspectos importantes, como as necessidades reais desse grupo, e a relação ser humano-ambiente são negligenciadas em função de outros. Por isso, identificar parâmetros aplicáveis à programação que sejam capazes de explorar novas soluções na concepção de projetos que enfoquem nessa relação, por meio de ferramentas BIM pode ser uma forma, de ao mesmo tempo que se otimiza tempo durante o processo de projeto ao diminuir atividades braçais repetitivas, se torne possível inserir elementos que vão além do que o descrito pelas normas de acessibilidade brasileiras.

Dessa forma, os parâmetros que estão sendo inseridos no plugin são resultado das pesquisas referentes à equalização teórica e à equalização prática, no qual abrangem aspectos em comum de normas de acessibilidade do Brasil e dos Estados Unidos e a preferência das PcDV em relação à pisos aplicados em projetos (Figura 7).

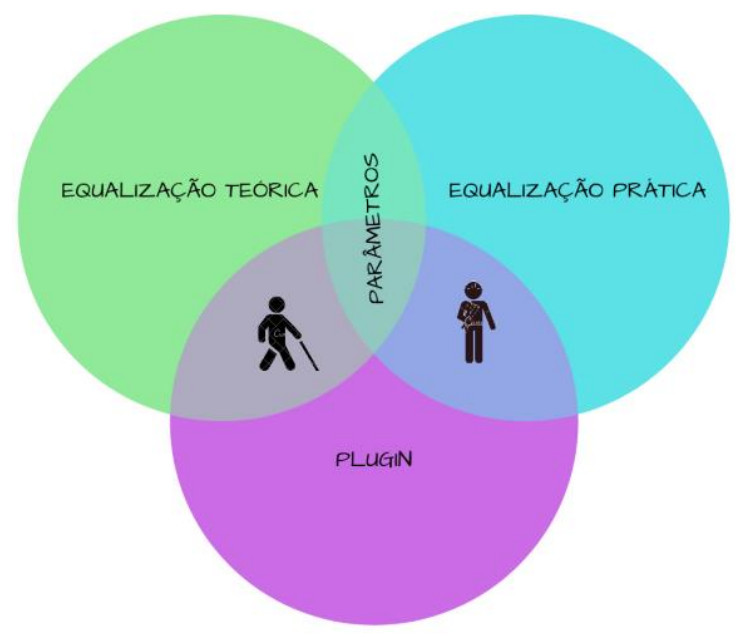

Figura 7 - Equalização dos aspectos abordados na pesquisa Fonte: Autores (2019)

\section{AGRADECIMENTOS}

Agradecimentos a Associação Passofundense de Cegos (APACE), ao Programa de Suporte à Pós-Graduação de Instituições de Ensino Particulares / Coordenação de Aperfeiçoamento de Pessoal de Nível Superior - Brasil 
(PROSUP/CAPES) e ao Núcleo de Inovação e Tecnologia em Arquitetura e Urbanismo (NITAU) do Programa de Pós-graduação em Arquitetura e Urbanismo da Faculdade Meridional (PPGARQ/IMED) pelo apoio recebido.

\section{REFERÊNCIAS}

ASSOCIAÇÃO BRASILEIRA DE NORMAS TÉCNICAS. NBR 16537: Acessibilidade Acessibilidade - Sinalização tátil no piso - Diretrizes para elaboração de projetos e instalação. $1^{\circ}$ ed. Rio de Janeiro, 2016. 52 p.

AUTODESK. Autodesk App Store. 2017. Disponível em: <https://apps.autodesk.com/RVT/en/Home/Index>. Acesso em: 11 nov. 2018.

BIANCHIN, M.; HEYLIGHEN, A. Just design. Design Studies. Elsevier, 2017.

Disponível em: <https://doi.org/10.1016/j.destud.2017.10.001>. Acesso em: 30 set. 2019.

BRÍGITTE, G.; RUSCHEL, R. Identification of applicable patterns to algorithmization in BIM to explore solutions in the design stage of Social Housing. XXI Congresso Internacional da Sociedade Iberoamericana de gráfica digital. v. 5, n. 1, p. 68-73. São Paulo. 2018. ISSN 2318-6968, DOI 10.5151/sigradi20181466.

DRESCH, A.; LACERDA, D. P.; ANTUNES JUNIOR, J. A. V. Design Science Research: A Method for Science and Technology Advancement. Springer International Publishing, 2015.

DYNAMO. About The Dynamo Primer. 2018. Disponível em: <http://dynamoprimer.com/en/>. Acesso em: 9 out. 2018.

CAIXETA, M. C. B. F.; FABRICIO, M. M. Métodos e instrumentos de apoio ao codesign no processo de projeto 111 de edifícios. Ambiente Construído, Porto Alegre, v. 18, n. 1, p. 111-131, jan./mar. 2018. Disponível em:

<http://dx.doi.org/10.1590/s1678-86212018000100212>. Acesso em: 30 set. 2019.

CARNEIRO, G.; BARROS, G.; ZIBEL, C. Design colaborativo de comportamentos para ambientes interativos. V!RUS, São Carlos, n. 6, dezembro 2011. Disponível em: <http://www.nomads.usp.br/virus/virus06/? sec=4\&item=8\&lang=pt>. Acesso em: 20 ago. 2018.

EASTMAN, C. Explorations of the cognitive processes in design. Pittsburgh: Dept. of Computer Science. Carnegie Mellon University, 1968.

HUDSON, R. Strategies for Parametric Design in Architecture: An application of led research. Tesis (Ph.D) - University of Bath, 2010.

JÚNIOR, V. H. C.; CELANI, G. From the automated generation of layouts to fabrication with the use of BIM: a new agenda for Architecture in the 21st century. In: XXII Congresso Internacional da sociedade Iberoamericana de gráfica digital-Sigradi. v. 5, n. 1, p. 23-30, nov. 2018. ISSN 2318-6968, DOI 10.5151/sigradi2018-1302

LAHAV, O.; MIODUSER, D. Blind persons ' acquisition of spatial cognitive mapping and orientation skills supported by virtual environment. Proc. 5th Internacional Conference Disability, Virtual Reality \& Assoc. Tech., Oxford, UK, 2004. 
LAHAV, O.; SCHLOERB, D. W.; SRINIVASAN, M. A. Integrate the BlindAid system in a traditional orientation and mobility rehabilitation program. Virtual

Rehabilitation International Conference, Israel, 29 Jun-2 Jul, 2009.

MUSSI, A. Q. Pesquisa BlinadAid do laboratório TouchLab do Massachusetts Institute of Technology (MIT). Entrevistado: Mandayan Srinivasan, nov. 2018.

NATIVIDADE, V. G.; VENTURA, A. Arquitetura Algoritmica: uma abordagem conceitual. In: XIII Congreso de la Sociedad Iberoamericana de Grafica Digital, 2009, São Paulo. Anais do XIII Congresso da Sociedade Ibero-americana de Gráfica Digital. São Paulo: Fapesp, 2009. p. 315-317.

O'LEARY, A.; LOCKWOOD, P.; TAYLOR, R. Evaluation of Detectable Warning Surfaces for Sidewalk Curb Ramps. Transportation Research Record: Journal of the Transportation Research Board, v. 1538, p. 47-53, 1996. doi:10.3141/1538-06

SCHWARTZ, P. H. Accessible and affordable housing--design, marketing, and management concerns of disabled individuals and community development corporations in Massachusetts. 1993. Tese - Departamento de Estudos Urbanos e Planejamento, Instituto de Tecnologia de Massachusetts (MIT), Massachusetts, Estados Unidos, 1993. 